\title{
Tackling Non-communicable Diseases in Asia Countries Systematic Review
}

\section{Matta Ernita and Adik Wibowo}

${ }^{1}$ Department of Health Policy and Administration, Faculty of Public Health, Universitas Indonesia, Depok, Indonesia

${ }^{2}$ Lecturer Faculty of Public Health, Universitas Indonesia, Depok, Indonesia

\section{Abstract}

NCDs impact the lives and health of many people, effective policies and program have to be put in tackling NCDs. This study aimed to find out the program and policies in asia countries. The method was a systematic review by using the search facility database online through uindonesia summon serialssolutions and Proquest by year of publication from 2007 to 2016. Journals were screened by tittle and abstract according to research topic, then selected using inclusion and exclusion criterias and at the end we found 8 journals to review. The epidemic of NCDs influence the universal health coverage in some countries. The ongoing program in tackling NCDs in southeast asia countries

Corresponding Author:

Matta Ernita

matta.ernita@ui.ac.id

Received: 21 December 2018

Accepted: 23 January 2019

Published: 28 February 2019

Publishing services provided by

Knowledge E

(c) Matta Ernita and Adik

Wibowo. This article is

distributed under the terms of

the Creative Commons

Attribution License, which

permits unrestricted use and

redistribution provided that the

original author and source are

credited.

Selection and Peer-review under the responsibility of the 3rd IMOPH \& the 1st YSSOPH Conference Committee. are a community based approach, improve the skill of health workers, increase an investment in public health intervention programs and involve all health sectors and related stakeholders. The policy maker should make the program that focus on health promotion, strengthening infrastructure including human resources and early diagnosis on diseases.

Keywords: tackling, non communicable diseases, policies, program

\section{Introduction}

WHO defines NCDs as including chronic diseases (principally cardiovascular diseases, diabetes, cancer, and asthma/chronic respiratory diseases), injuries and mental health. NCDs is a chronic conditions that do not result from an (acute) infectious process and hence or not communicable, that has a prolonged course, that does not resolve spontaneously, and for which a complete cure is rarely achieved (CDC).

Four behavioral risk factors for NCDs are: physical inactivity, tobacco use, alcohol use and unhealthy diets. The problem of NCDs continues to increase in all regions of the world and it is need the best health policies and programs. NCDs are probably the most important health threat the world is confronting in terms of "single" cause of death, disease and disability (although NCDs are not one but many diseases, as is well known) [1]. Evidence shows that NCDs are to a great extent preventable. Government has to make difficult choices on how best to allocate resources for health and health care [2].

NCDs are becoming the dominant causes of death and disability worldwide. Three G OPEN ACCESS 
services utilization in Bangladesh, in particular, and South-East Asia,moregenerally: cardiovascular disease, diabetes and tobacco-related illness [3]. Most NCDs deaths are preventable and health systems are inadequate or unprepared in tackling NCDs.

\section{Methods}

The method was a systematic review by using the search facility database online through uindonesia summon serialssolutions and Proquest by year of publication from 2007 to 2016. Search using a specific keyword is "tackling" AND " non communicable diseases" AND :policies" AND "program". All journals were screened by free full text, article journal, year of publication and location. And then journals that have been further filtered were screened by reading tittle and abstract.

\section{Results}

We found 2137 journals by using data base online through Indonesia summon online and Proquest by using keywords: tackling, non communicable diseases, policies and program, 1052 journals were found from Uindonesia summon online and 1085 journals form Proquest. Then we screened by free full text, article journal, year of publication and location. At the end we found 8 journals to review (fig.1). Two studies from India and each one from Indonesia, Turkey, Bangladesh, Nepal, China and Iran.

Based on article reviewed, eight studies revealed that policies and program on tackling NCDs in Asia countries were need a health system approach that include all health sectors, related stakeholders and non government organization. The ongoing program in tackling NCDs in asia countries are a community based approach, improve the skill of health workers, increase an investment in public health intervention programs and involve all health sectors and related stakeholders. The policy maker should make the program that focus on health promotion, strengthening infrastructure including human resources and early diagnosis on diseases.

\section{Discussion}

Most NCDs are associated with preventable risk factors. Effective control of risk factors could reduce the incidence of heart attack, stroke and DM by at least $80 \%$ [4]. How to increase the awareness of health in community still be a problem nowdays in many countries in asia. Despite the good progress made to control and prevent NCDs, great challenges remain in China. One challenge is poor knowledge and low awareness about NCDs, particularly at the poor and rural community level [4].

Therefore, to control CVD in low and middle income country, investigations of a community-based primary- prevention of CVD risk factors are needed [5]. The government should strengthen the skill of health workers especially in promote and educate community. Generating national and sub-national information and monitor the trends of NCDs and their risk factors, establishing health promotion programs across the life 

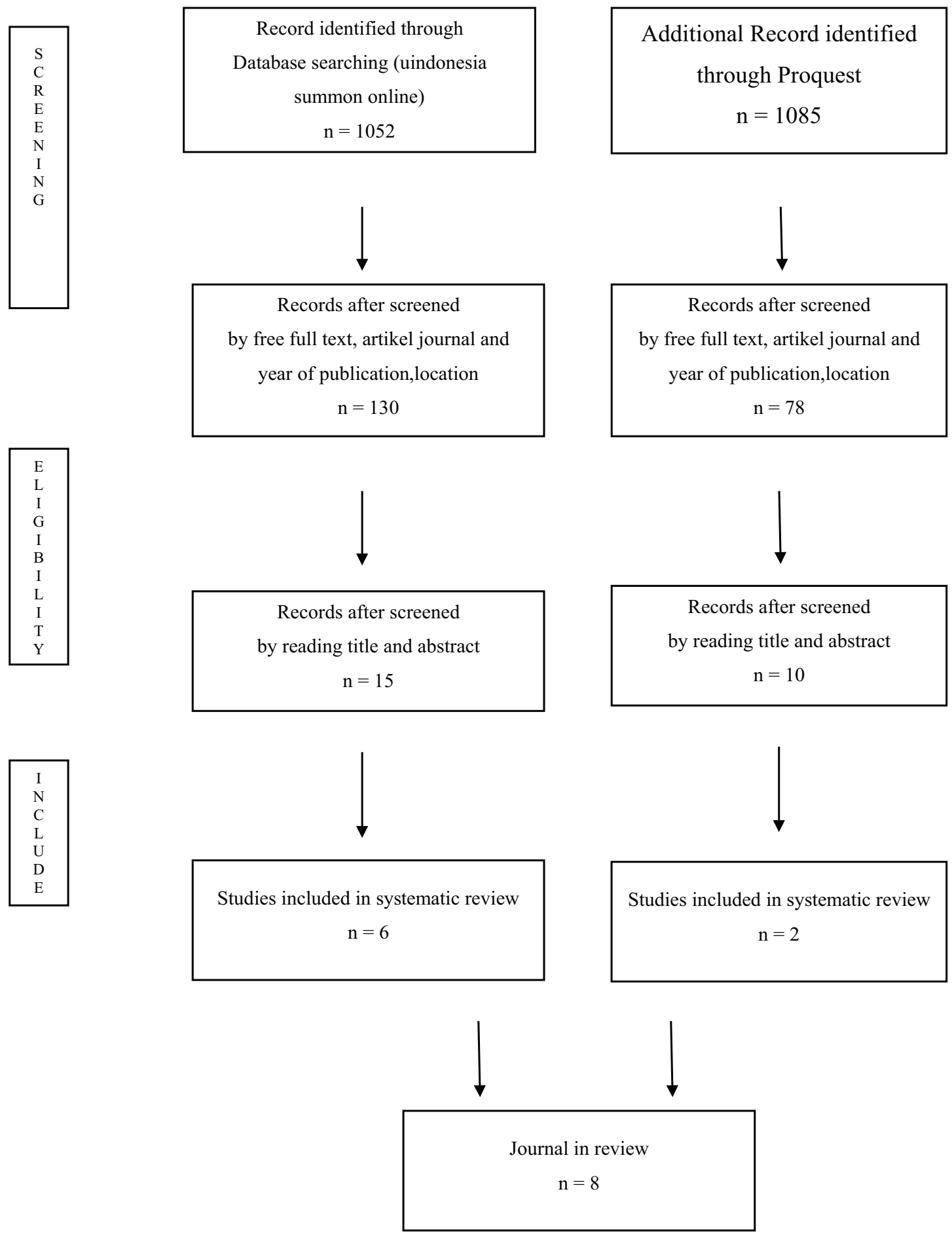

Figure 1: Systematic Review Flowchart.

course through pri- mary health care system and universal health coverage components, and tackling issues through multi-sectoral approach are critical strategies be suggested [6].

The focusses of tackling NCDs is still in treatment rather than educate and promote. Although these services are essential to save the lives of those who are already diseased, they have not helped to slow down the growing epidemic of CVDs in the country 


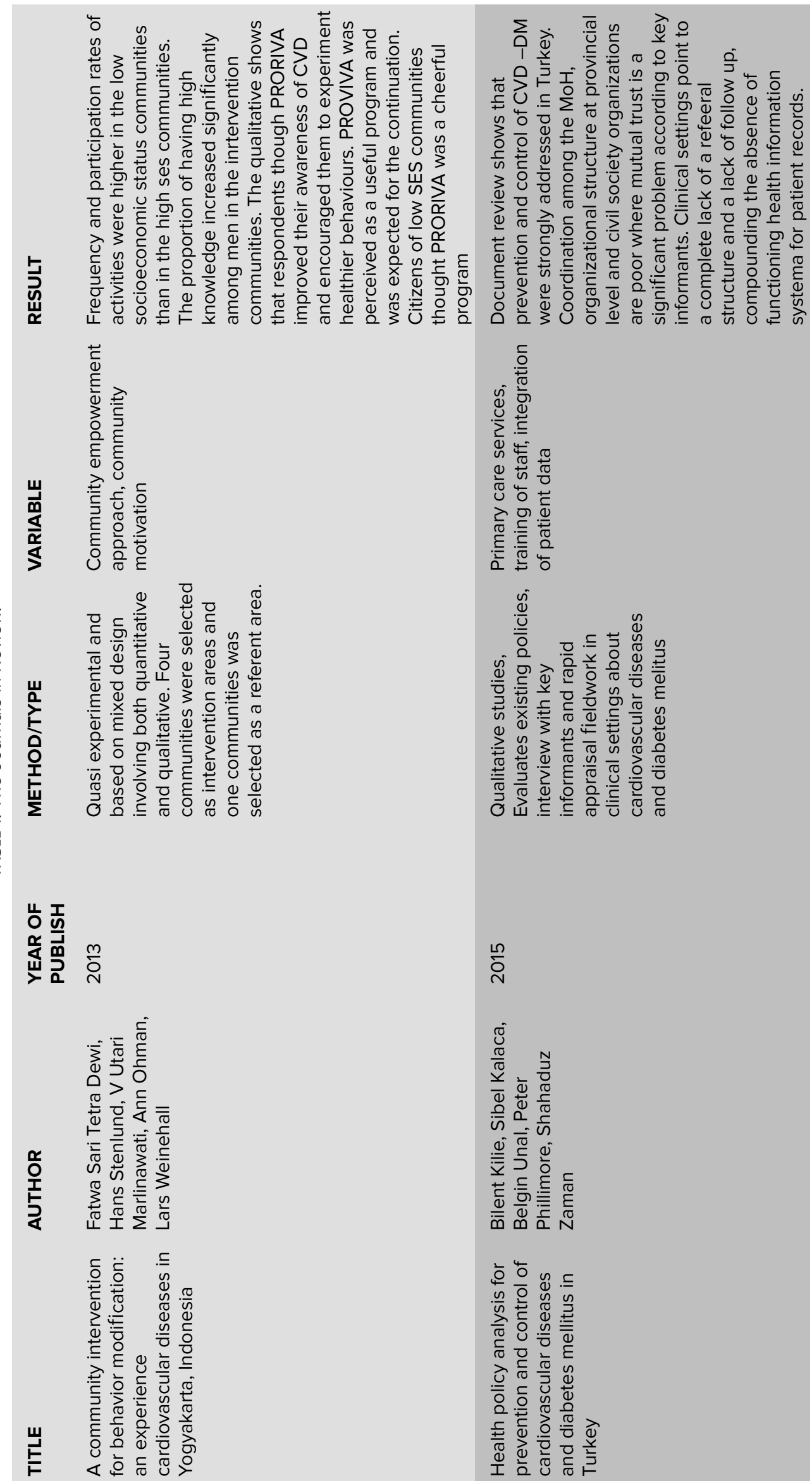




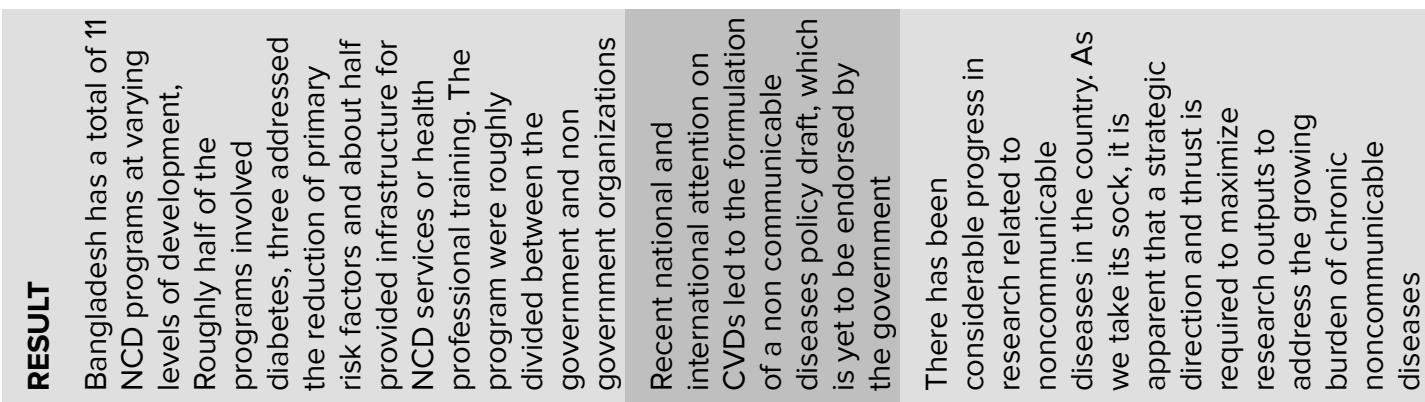

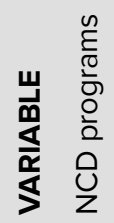

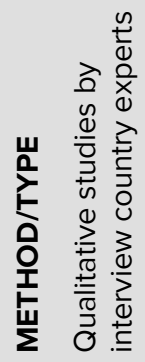

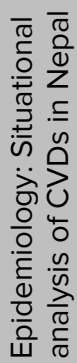

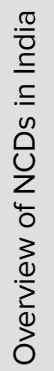

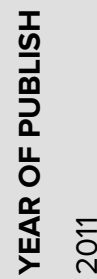

స్̀

$\overline{\grave{o}}$

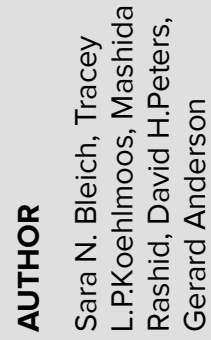

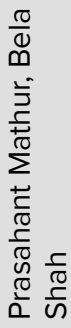

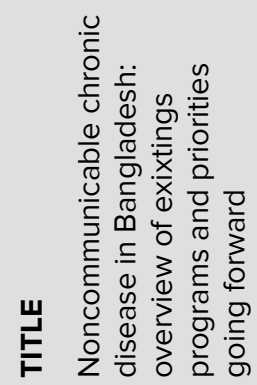

$\frac{0}{20}$
$\frac{0}{10}$
$\frac{7}{70}$
$\frac{5}{10}$
$\frac{1}{4}$

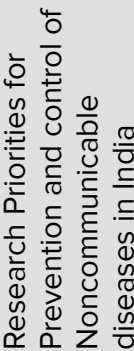



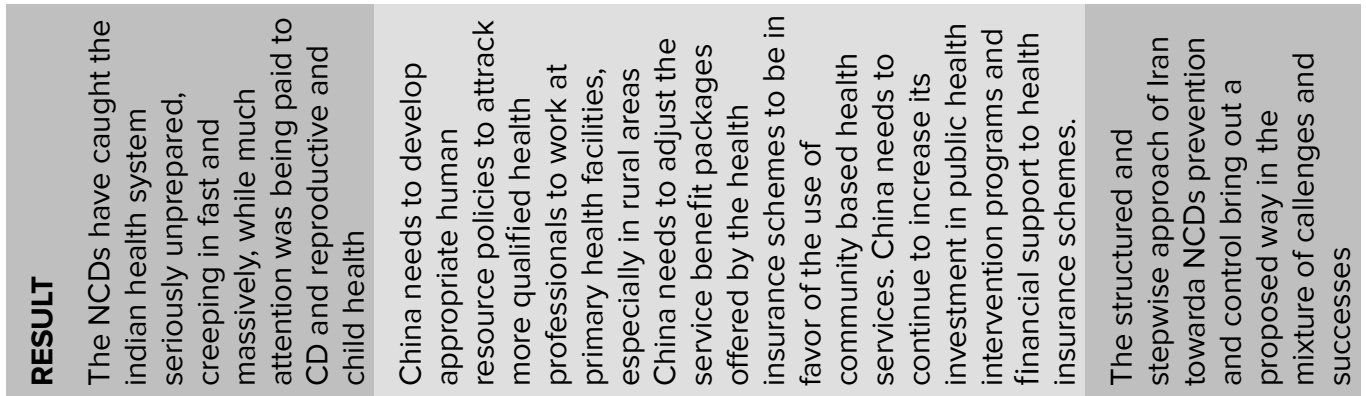

岁

$\frac{0}{0}$
$\frac{1}{4}$
3
0
$\frac{0}{2}$
$\alpha$
$\alpha$

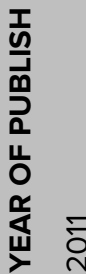

$\frac{\frac{U}{U}}{\frac{U}{4}}$

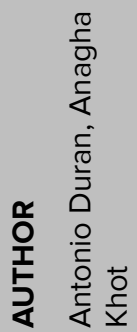

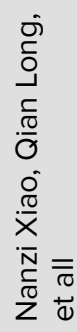

๙ิ
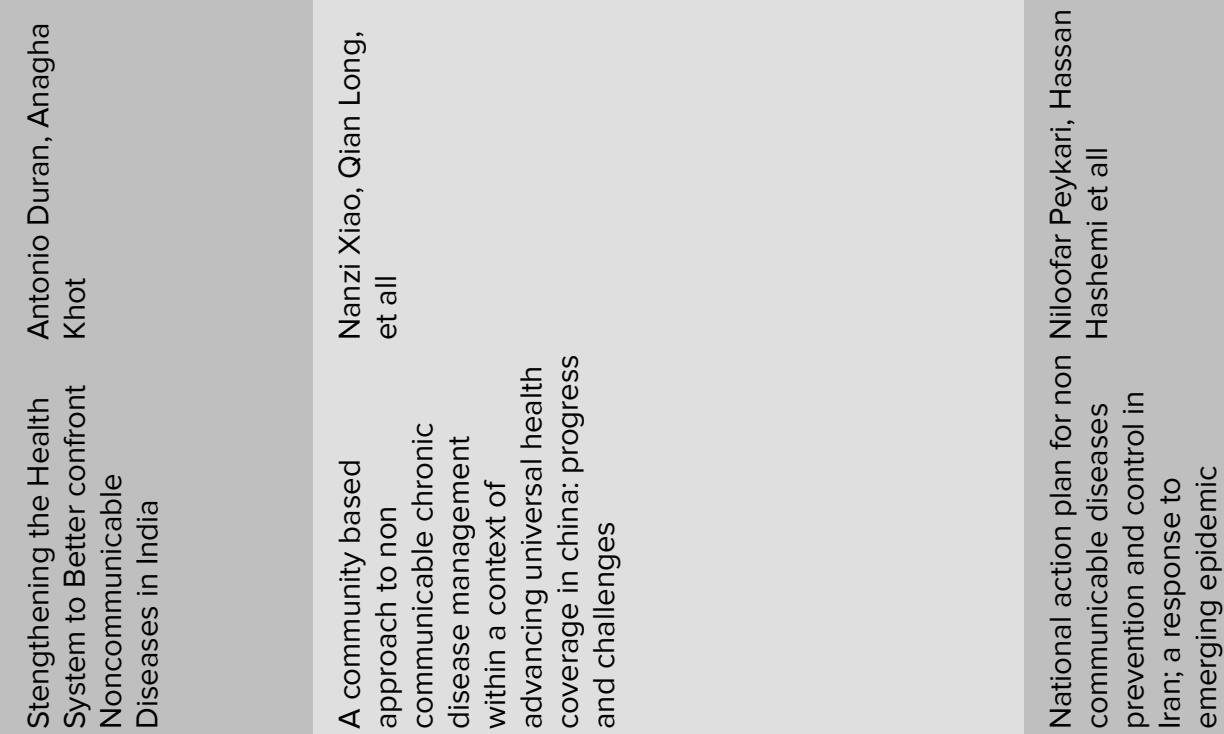
[7]. Establishment of alternative, low cost and feasible strategies for screening and early diagnosis of NCDs for their optimal use in health system settings [8].

Reducing the risk factors for NCDs through health promotion and primary prevention, involvement of the community and creation of an enabling environment are crucial for bringing about a sustained behavior change.

\section{Conclusions}

The burden of NCDs is impact the development of a country, financial burden that appear will allocate more in tackling NCDs. Need a strong commitment from government in tackling NCDs, involve all stakeholders to contribute. Educate people to live in a healty live by reduce the risk factor of NCDs. Strengthening the health care system by improve the capacity of health worker, allocate more public health intervention program. Give an intervention to population based intervention rather than those at high risk individuals. The burden of NCDs is contributing to poverty and has become a barrier to development and achievement of the SDGs.

\section{References}

[1] Khot A, Duran A. Strengthening the Health System to Better Confront Noncommunicable Diseases in India. Indian J Community Med. 2011;36(5):32.

[2] Faiz MA, Rahmanb MR, Karim MN. Prioritizing Policy Approach and Actions to Address Epidemic of Non Communicable Diseases (NCDs). J Bangladesh Coll Physicians Surg. 2012;30.

[3] Bleich SN, Koehlmoos TLP, Rashid M, Peters DH, Anderson G. Noncommunicable chronic disease in Bangladesh: Overview of existing programs and priorities going forward. Health Policy (New York) [Internet]. 2011;100(2-3):282-9. Tersedia pada: http://dx.doi.org/10.1016/j.healthpol.2010.09.004

[4] Xiao N, Long Q, Tang X, Tang S. A community-based approach to non-communicable chronic disease management within a context of advancing universal health coverage in China: progress and challenges. BMC Public Health. 2014;14(Suppl 2):S2.

[5] Tetra Dewi FS, Stenlund H, Marlinawati VU, Öhman A, Weinehall L. A community intervention for behaviour modification: an experience to control cardiovascular diseases in Yogyakarta, Indonesia. BMC Public Health. 2013;13(1):1043.

[6] Peykari N, Hashemi H, Dinarvand R, Haji-Aghajani M, Malekzadeh R, Sadrolsadat A, et al. National action plan for non-communicable diseases prevention and control in Iran; a response to emerging epidemic. J Diabetes Metab Disord. 2017;16(1):3.

[7] Vaidya A. Tackling cardiovascular health and disease in Nepal: epidemiology, strategies and implementation. Heart Asia. 2011;87-92.

[8] Shah B, Mathur P. Research Priorities for Prevention and Control of Noncommunicable Diseases in India. Indian J Community Med. 2011;36(5):72. 